\title{
Luitenant-Kolonel Helperus Andreas (Pierre) van Ryneveld en die Onderdrukking van die Rehoboth-Baster-Opstand in Suidwes-Afrika (Namibië), April 1925'
}

\author{
G.J.J. OOSTHUIZEN \\ DEPARTEMENT GESKIEDENIS, PU VIR CHO
}

\begin{abstract}
In spite of opposition the Baster Council accepted a constitutional Agreement in August 1923. The malcontents initiated an effective rebellious action by electing their own Council (New Council) to manage the Rehoboth Gebiet. The helpless Old Council finally capitulated. Efforts at mediation by Prime Minister Hertzog were largely unsuccessful, and in December 1924 the South African Government was faced with a unilateral declaration of independence. In retaliation the Baster constitution was suspended and the Rehoboth Gebiet placed under a white Magistracy. The New Council, however, went on undisturbed with the management of the Rehoboth Gebiet. In April 1925, with a demonstration of power, the South African Government forced a showdown and with no loss of life subjected the rebels to their authority. In this military action, Pierre van Ryneveld and his "daring young men in their flying machines" played a major and decisive role.
\end{abstract}

\section{Pierre van Ryneveld: Lugmagpionier}

\footnotetext{
Luitenant-kolonel Pierre van Ryneveld, gebore op 2 Mei 1891 te Senekal in die Oranje-Vrystaat, is veral bekend omdat hy en luitenant Quintin Brand in 1920 die eerste persone was om die afstand van Londen na Kaapstad via Kaïro en die vasteland van Afrika suksesvol per vliegtuig af te lê. ${ }^{2}$ In dieselfde jaar het hy in opdrag van die destydse Suid-Afrikaaanse Eerste Minister, generaal J.C. Smuts, die Suid-Afrikaanse Lugmag in die lewe geroep. In Junie 1920 word hy dan ook as Direkteur van die pasgestigte Suid-Afrikaaanse Lugdienste,
}

terugwerkend vanaf 1 Februarie 1920, aangestel. ${ }^{3}$ Van Ryneveld het veel gedoen om die Lugmag uit te bou en as ' $n$ gewaardeerde en ontontbeerlike afdeling van die Suid-Afrikaanse Weermag (toe Unieverdedigingsmag) te vestig. Hy het ook ' $n$ besondere rol gespeel in die onderdrukking van verskeie opstande in Suider-Afrika. Só byvoorbeeld is sy aandeel in die onderdrukking van die Randse mynwerkerstaking en die Bondelswart-opstand in Suidwes-Afrika van 1922 welbekend. ${ }^{4}$ Sy deurslaggewende rol in die onderdrukking van die RehobothBaster-opstand in Suidwes-Afrika gedurende April 1925 ressorteer egter, ten spyte van die internasionale rimpelinge wat daardeur veroorsaak is, onder enkele van die inligtingstiltes rakende Pierre van

'n Spesiale woord van dank kom prof. P.D. van der Walt (emeritus-professor, PU vir CHO) toe vir die taalkundige versorging en nuttige wenke ter verbetering van die finale produk.

K. Willers, "Avontuurlike baanbrekersvlug", Militaria, 1991, 21:3, p. 1

K. Willers, "Avontuurlike baanbrekersvlug"..., p. 4; J.P.B. van Loggerenberg, "Sir Pierre van Ryneveld memorial lecture: The role of air power in Southern Africa", Strategic Review for Southern Africa, May 1991, 13:1, p. 41

C.J. Beyers (hoofred.), Suid-Afrikaanse Biografiese Woordeboek, deel V (Creda Press, Pretoria, 1987), p. 878. 


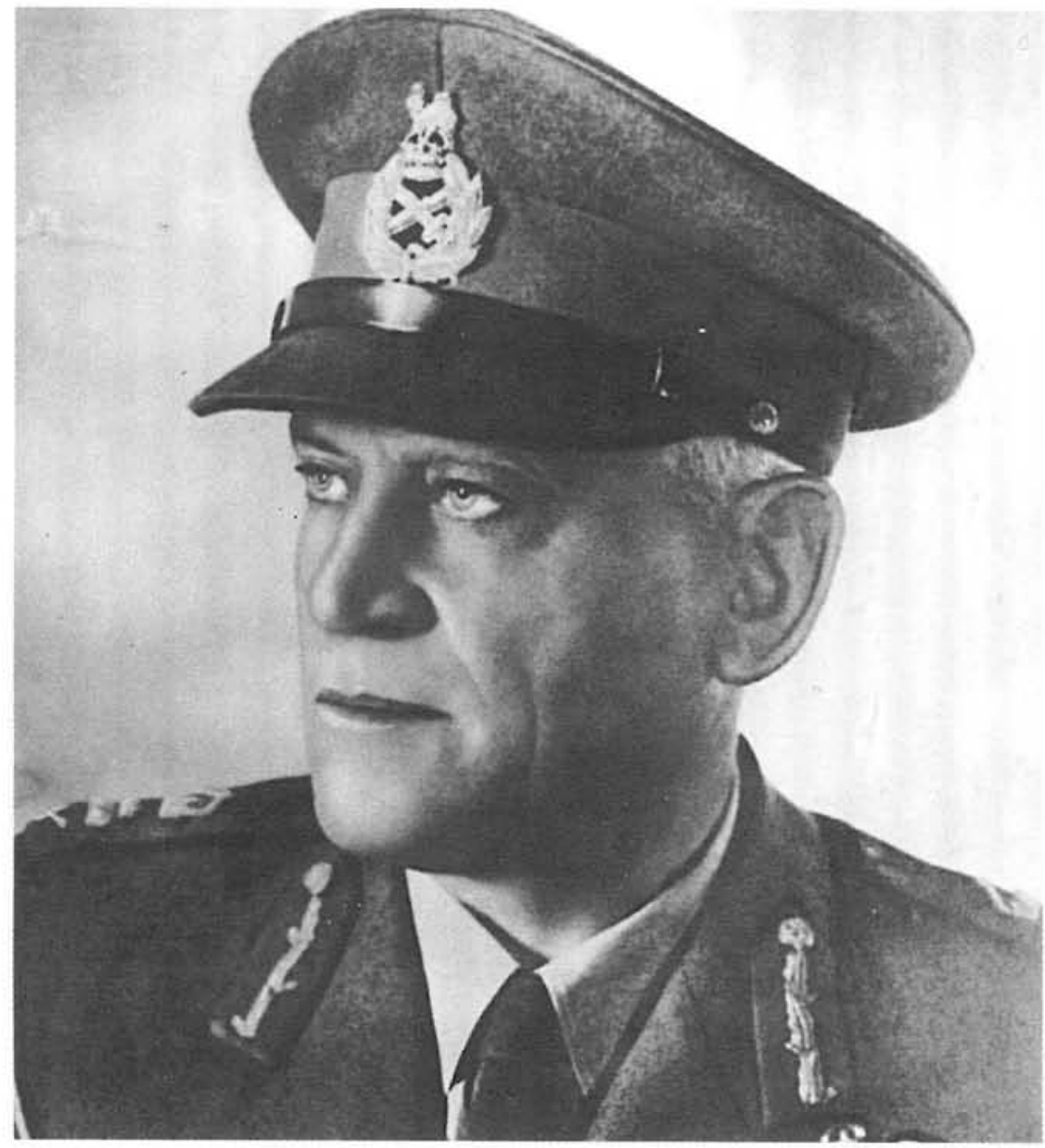

Pierre van Ryneveld

SANW Argief

Ryneveld. Selfs die hoogaangeskrewe Suid-Afrikaanse Biografiese Woordeboek ${ }^{5}$, wat 'n skets oor Van Ryneveld bevat, verswyg dié gebeure.

\section{Die posisie van die Rehoboth-basters voor April 1925}

Dié groep mense, afstammelinge van blanke vaders en Khoikhoi-moeders, het in 1868 die Kaapkolonie verlaat en hulle in 1870/71 in Rehoboth en omgewing in Suidwes-Afrika gevestig en mettertyd ' $n$ vorm van selfregering binne die grense van hulle eie gebied tot stand gebring, veral deur ' $n$ verdrag met die Duitse owerheid. Gedurende die Eerste Wêreldoorlog is Duitsland deur Suid-Afrika as maghebber in Suidwes-Afrika vervang. Kenmerkend van die aanvangsfase van Suid-Afrikaanse bestuur in Suidwes-Afrika was die gesloer om helderheid te kry oor die konstitusionele posisie van die Rehoboth-Basters. Eers in Januarie 1922 is ' $n$ konsep- ooreenkoms, opgestel deur die Suidwes-Afrikaanse Administrasie (hierna Administrasie), aan die Basterraad voorgelê. Dié voorgestelde ooreenkoms was egter nie vir die Bastergemeenskap aanvaarbaar nie, maar die Basterraad is as't ware deur Administrateur Hofmeyr gestoomroller om die ooreenkoms téén die wil van die meerderheid Basters te onderteken en is gevolglik in ' $n$ onhoudbare posisie geplaas. Die Raadslede het hulle daardeur die wrewel van die meerderheid Basters op die hals gehaal en is soos melaatses deur die ontevredenes behandel. ${ }^{6}$

Die ontevredenes het met ' $n$ effektiewe versetaksie begin en ' $n$ eie Raad (Nuwe Raad) verkies. ${ }^{7}$ Die versetaksie was inderdaad so suksesvol dat lede van die Ou Raad magteloos moes toekyk hoe die ontevredenes die Rehoboth-Gebiet bestuur. ${ }^{8}$ Uiteindelik het 'n moedelose Ou Raad in Julie 1924 die handdoek ingegooi en is die Administrasie ver- 


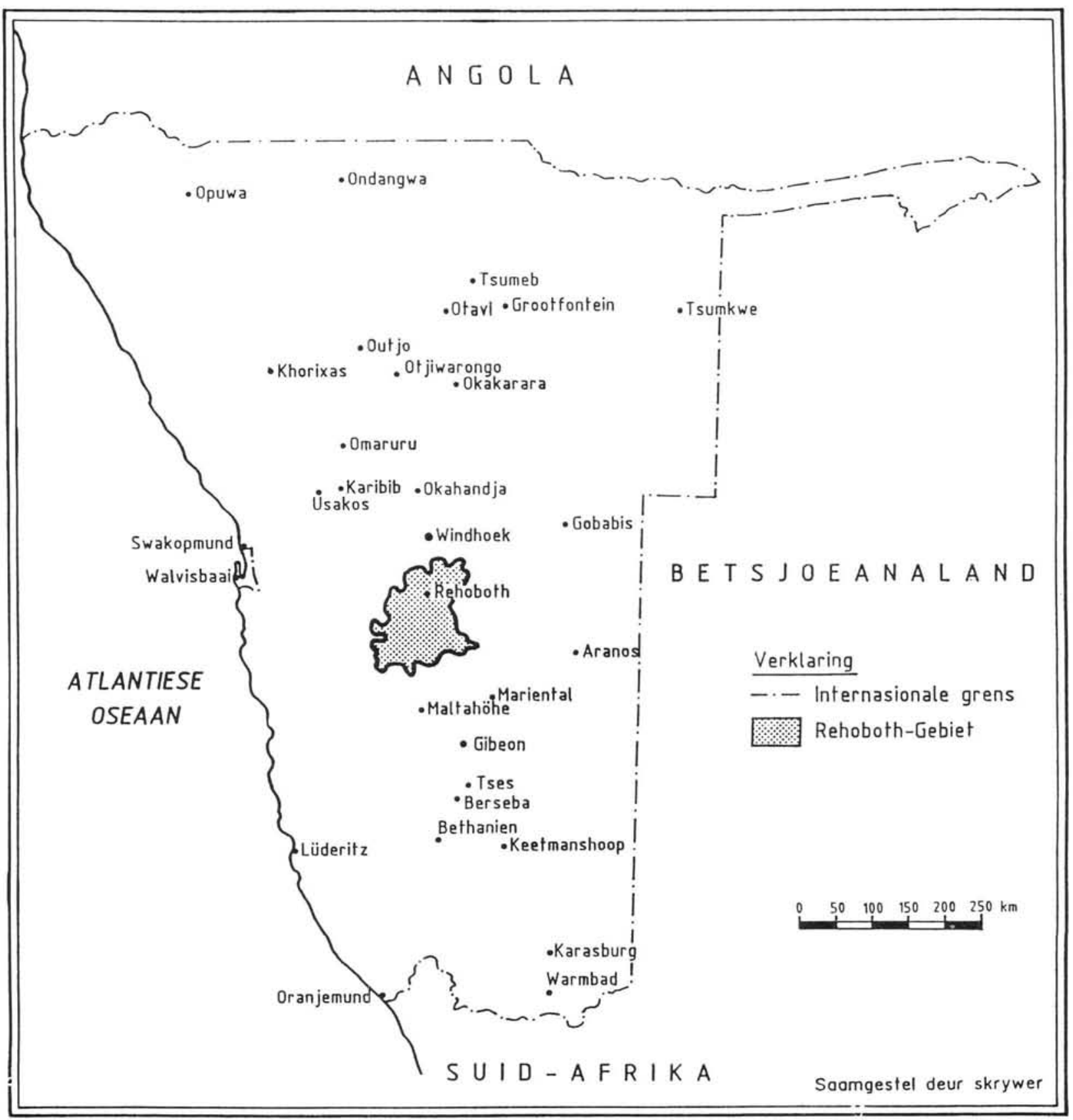

Ligging van die Rehoboth-Gebied in Suidwes-Afrika (Namibië)

soek om tydelik die bestuur van die RehobothGebiet oor te neem. ${ }^{9}$

Bemiddelingspogings van Eerste Minister Hertzog gedurende Augustus ${ }^{10}$ en November $1924^{11}$ is met weinig sukses bekroon. Die Nuwe Raad het hom kort na die November 1924-besoek van Hertzog op die Volkebond beroep ${ }^{12}$, en het ondanks verdere bemiddelingspogings deur die Administrateur, die Administrasie op 1 Desember 1924 met ' $n$ eensydige onfhanklikheidsverklaring gekonfronteer. ${ }^{13}$

As teenvoeter vir die uitdagende onafhanklikheidsverklaring van die Nuwe Raad het die Administrasie

9 NAWA219:9, Brief Kapitein en Raad/Magistraat, 11.07.1924; A312:17/61, Letter H.P. Smit/Administrator, 14.07.1924, p. 2.

10 NAW SWAAA206/3 Bastard Gebiet Rehoboth. Rehoboth Matters ( $v o l$ 2)/SWAA 2/18/2 Unregistered Correspondence and Papers, Rehoboth Affairs, Documents numbered 1-49, Verslag van onderhoud tussen die Eerste Minister en vyf afgevaardigdes van Rehoboth, S.W.A. op Saterdag, 2 Augustus, 1924 (document 48).

" NAW SWAAA206/3 Bastard Gebiet Rehoboth. Rehoboth Matters (vol 5), Vergadering op Rehoboth, 10 Nov. 1924, met die "ou" seksie van die kleurlingburgers [Vergadering met die "Nuwe" seksie]; Allgemeine Zeitung, 17.11.1924

12. League of Nations Archives, Geneva (LNA), 1919-1927, 1/1347/37888, Petition N. van Wyk et al./ Secretariat of the League of Nations, 13.11.1924.

13 NAW SWAAA206/3 Bastard Gebiet Rehoboth. Rehoboth Matters (vol. 5), Brief Parlementsraad en Volksraad/Magistraat, 1.12.1924 (Enclosure 1 to Letter Magistrate/Secretary for South West Africa, 1.12.1924); Kyk ook LNA, 1919-1927, 1/1347/37888, Memorandum upon petition dated 13th November 1924 addressed to the League of Nations by certain burghers of the Rehoboth community, 16.01.1925 (Annexure G). 
die Rehoboth-Gebiet onder blanke Magistraatsbestuur geplaas, en die pligte en bevoegdhede van die Basterkaptein en -raad is met ingang van 16 Desember 1924 aan magistraat C.N. Manning toevertrou. ${ }^{14}$ Die Nuwe Raad het egter in Januarie 1925 weer hulle eie bestuursliggame verkies en voortgegaan om die administrasie van die Rehoboth-Gebiet te behartig. Herhaaldelike waarskuwings van die Administrasie is deur die opstandelinge in die wind geslaan. ${ }^{15}$

Dié onversetlike houding van die Nuwe Raad en sy ondersteuners en die openlike uitdaging van die Administrasie kon egter nie onbepaald voortduur nie, en daarom het die Administrasie besluit om enkele invloedryke leiers van die ontevredenes kragtens die Veebrandmerkwet te vervolg. ${ }^{16} \mathrm{Al}$ hoewel die eerste twee sogenaamde toetssake sonder veel probleme verloop het, het verdere vervolging hewige teenkanting van die ontevredenes uitgelok. Hulle het summier geweier om gedagvaarde persone uit te lewer. ${ }^{17}$

'n Dringende oproep van die Eerste Minister aan die ontevredenes om hulle aan die gesag van die Administrasie te onderwerp ${ }^{18}$ is uitdagend begroet met ' $n$ hernieude verwerping van die Ooreenkoms. ${ }^{19}$ Dit was duidelik dat die opstandelinge nie maklik sou bes gee nie en dat fisiese geweld uiteindelik sou losbars.

\section{Mobilisering van die polisie- en burgermag}

Weens die onversetlike houding van die Nuwe Raad en hulle ondersteuners het die Administrasie besluit om sowel die polisie- as die burgermag te mobiliseer. Majoor C. A. van Coller, Streeksinspekteur

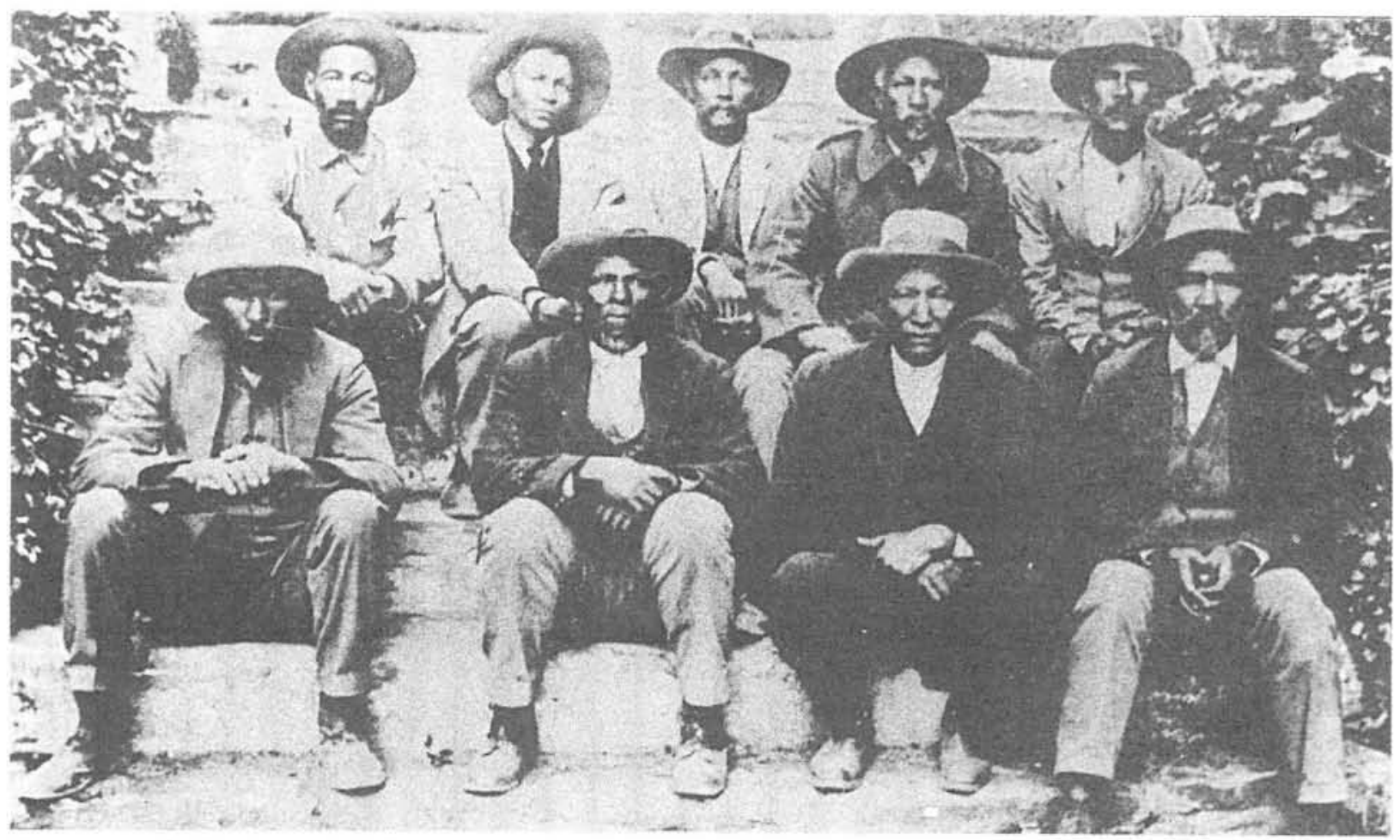

Sewe van die Basterraadslede op die foto het die Ooreenkoms van 17 Augustus 1923 onderteken.

V.I.n.r. agter is G. Alcock, F Maasdorp (Sekretaris), T. Jarman, P. Mouton en M. McNab. Voor sit v.l.n.r. J. Witbooi, P. Beukes, A. Mouton (waarnemende Kaptein) en G. Cloete. Net Alcock en Jarman het nie die Ooreenkoms onderteken nie. Die ander twee ondertekenaars was N. Olivier en G. de Klerk.

14 Buitengewone Officiële Koerant van Zuidwest Afrika, 10.12.1924, pp. 1879-1881; Allgemeine Zeitung, 13.12. 1924; The Times, 4.04.1925.

15 G.J.J. Oosthuizen, Die Rehoboth-Basters..., p. 316

16 NAW SWAAA206/3 Bastard Gebiet Rehoboth. Rehoboth Matters (vol. 6), Telegram Hoofd/Secretary [for South West Africa], 5.03.1925; Telegram Hoofd/Secretary [for South West Africa], 9.03.1925, pp. 1-2; NAW SWAAA206/3 Bastard Gebiet Rehoboth. Rehoboth Matters (vol. 5), Dringende Kennisgewing BRANDMERKEN VAN VEE (Beeste), 17.01.1925 (Annexure to Letter Magistrate/Secretary for South West Africa, 18.01.1925); The Windhoek Advertiser, 18.02.1925.

17 NAW SWAAA206/3 Bastard Gebiet Rehoboth. Rehoboth Matters (vol. 3), Telegram Magistrate/Secretary [for South West Africa], 26.03.1925; SWAAA206/3 Bastard Gebiet Rehoboth. Rehoboth Matters (vol. 6), Brief D. Beukes et al./Magistraat, 26.03.1925

18 NAW A312:20/79, Telegram Hoofd/Magistraat Manning, 30.03.1925, pp. 1-3, 5-6.

19 U.G. 33-1925, Rapport van de Administrateur van Zuidwest Afrika voor het Jaar 1924, p. 13; W.H. Weber, Die regsposisie van die Rehoboth-Basters (D.Phil., US, 1946), p. 115. 
van die Suidwes-Afrika-Polisie, is beveel om so spoedig moontlik ' $n$ polisiekontingent in gereedheid te bring. ${ }^{20}$ Sy opdrag is bemoeilik deur ' $n$ nypende tekort aan perde weens die uitbreek van perdesiekte sowel as verspoelde paaie en spoorlyne. ${ }^{21}$ Ten spyte van hierdie remmende faktore het die polisiekontingent, bestaande uit 137 blankes en 20 nieblankes en toegerus met twee Maksim- en twee Lewismasjiengewere, reeds op Woesdag 1 April 1925 in Rehoboth aangekom. ${ }^{22}$ Met die aankoms van Van Coller is die lasbriewe vir die inhegtenisname van die elf persone, wat die Nuwe Raad nog steeds geweier het om uit te lewer, aan hom oorhandig. ${ }^{23}$ Van Coller het nie dadelik probeer om die persone te arresteer nie maar wyslik die koms van die burgermageenhede, wat intussen gemobiliseer is, afgewag.

Kolonel M. J. de Jager is op 31 Maart aangestel as opperbevelvoerder van die Rehoboth-veldtog. Ter ondersteuning van die polisie is die burgermageenhede van die distrikte Aroab, Bethanie, Gibeon, Keetmanshoop, Maltahöhe, Okahandja, Warmbad, Windhoek en Rehoboth op 1 April 1925 gemobiliseer, ${ }^{24}$ en twee dae later is krygswet kragtens Proklamasie 9 van 1925 in die Rehoboth-Gebiet en omringende distrik ingestel. ${ }^{25}$

Die mobilisering van die burgermag, wat in daardie stadium in sy kinderskoene was, het hoë eise aan kolonel De Jager gestel. Boonop is sy taak bemoeilik deur die groot afstande wat afgelê moes word, die nypende tekort aan perde en omdat die Suidwes-Afrikaanse Spoorweë, wat grootliks verantwoordelik was vir die vervoer van die troepe na
Rehoboth, probleme ondervind het weens verspoelings en ' $n$ ernstige tekort aan steenkool. Laasgenoemde probleem was te wyte aan verspoelings, wat die spoorverkeer tussen Suid-Afrika en Suidwes-Afrika erg ontwrig het. ${ }^{26}$

Ondanks genoemde probleme het die Spoorwegpersoneel hulle deeglik van hul taak gekwyt. Teen Saterdag 4 April 1925, dit wil sê binne 72 uur, was daar reeds 36 offisiere en 428 onderoffisiere en manskappe, van wie slegs 108 berede was, by Rehoboth-stasie byeen. ${ }^{27}$

\section{Toetrede van die Suid-Afrikaanse Lugmag}

Op versoek van Administrateur Hofmeyr is drie vliegtuie deur die Suid-Afrikaanse Regering na Rehoboth gestuur. ${ }^{28}$ Die lugmagkontingent, bestaande uit ses offisiere en 15 onderoffisiere en manskappe ${ }^{29}$ en onder bevel van luitenant-kolonel Pierre van Ryneveld, Direkteur van Lugdienste van die UnieVerdedigingsmag, het op 1 April 1925 per spoor na Rehoboth vertrek. ${ }^{30}$ Weens die verspoeling van ' $n$ gedeelte van die brug oor die Oranjerivier by Upington ${ }^{31}$ is die vliegtuie by Louisvale aanmekaargesit en vandaar na Keetmanshoop gevlieg om Rehoboth-stasie op Saterdagmiddag 4 April 1925 te bereik. ${ }^{32}$

Hofmeyr het ondertussen inderhaas van Kaapstad na Rehoboth vertrek en is op 2 April 1925 teen omstreeks 04:00 per boot oor die Oranjerivier. ${ }^{33} \mathrm{Hy}$ het Rehoboth die volgende dag per trollie bereik. ${ }^{34}$

20 NAW SWAAA206/3 Bastard Gebiet Rehoboth. Rehoboth Matters (vol 3), Letter Divisional Inspector, South West Africa Police/ Secretary for South West Africa, 24.03.1925, p. 1; U.G. 33-1925, Rapport van de Administrateur van Zuidwest Afrika voor het Jaar 1924, p. 12.

21 NAW SWAAA206/3 Bastard Gebiet Rehoboth. Rehoboth Matters (vol 6), Telegram Secretary [for South West Africa]/Hoofd, 30.03.1925, p. 1; The Windhoek Advertiser, 4.04.1925.

22 NAW SWAAA206/3 Bastard Gebiet Rehoboth. Rehoboth Matters (vol 7a), Report Colonel M.J. de Jager/Secretary for South West Africa, 16.06 .1925 , p. 5.

23 NAW SWAAA206/3 Bastard Gebiet Rehoboth. Rehoboth Matters (vol 7), Memorandum for major van Coller..., 1.04.1925.

24 NAW SWAAA206/3 Bastard Gebiet Rehoboth. Rehoboth Matters (vol 6), Telegram Secretary [for South West Africa]/Magistrates Keetmanshoop, Gibeon, Maltahöhe, Bethanie, Warmbad and Aroab, 27.03.1925; Officiële Koerant van Zuidwest Afrika, 1.04.1925, p. 2020; The Windhoek Advertiser, 1.04.1925; Allgemeine Zeitung, 1.04.1925.

25 Buitengewone Officiële Koerant van Zuidwest Afrika, 3.04.1925, pp. 2027-2028; Allgemeine Zeitung, 6.04.1925.

26 NAW SWAAA206/3 Bastard Gebiet Rehoboth. Rehoboth Matters (vol 7a), Report Colonel M.J. de Jager/Secretary for South West Africa, 16.06.1925, pp. 3-4, 9.

27 NAW SWAAA206/3 Bastard Gebiet Rehoboth. Rehoboth Matters (vol 7a), Report Colonel M.J. de Jager/Secretary for South West Africa, 16.06 .1925$, pp. 3, 8 .

28 U.G. 33-1925, Rapport van de Administrateur van Zuidwest Afrika voor het Jaar 1924, p. 13; Argief van die Suid-Afrikaanse Nasionale Weermag, Pretoria (SANW) Verkorte jaarverslag van die Departement van Verdediging diensjaar tot 30 Junie 1925, p. 2; Allgemeine Zeitung, 4.04.1925; Rand Daily Mail, 3.04.1925; The New York Times, 4.04.1925.

29 Cape Times, 7.04.1925.

30 SANW DC 1026:573/9, Circular Chief of the General Staff/adjutant General et al., 1.04.1925; Letter Financial under Secretary/ Director of Air Services, 26.03.1927, p. 1; Cape Argus, 3.04.1925.

${ }^{31}$ NAW SWAAA206/3 Bastard Gebiet Rehoboth. Rehoboth Matters (vol 7), Telegram Administrator/Secretary [for South West Africa], 2.04.1925, p. 1.

32 SANW, Verkorte jaarverslag van die Departement van Verdediging diensjaar tot 30 Junie 1925, p. 24; NAW SWAAA206/3 Bastard Gebiet Rehoboth. Rehoboth Matters (vol 7a), Report Colonel M.J. de Jager/Secretary for South West Africa, 16.06.1925, p. 14.

33 NAW SWAAA206/3 Bastard Gebiet Rehobuth. Rehoboth Matters (vol 7), Letter Secretary for South West Africa/General Manager Railways and Harbours, 2.04.1925.

34 NAW SWAAA206/3 Bastard Gebiet Rehoboth. Rehoboth Matters (vol 7), Telegram Hoofd (Rehoboth)/Hoofd (Cape Town), 3.04.1925; NAW SWAAA206/3 Bastard Gebiet Rehoboth. Rehoboth Matters (vol 7a), Report Colonel M.J. de Jager/Secretary for South West Africa, 16.06.1925, p. 9. 
Met groeiende onrus het die Nuwe Raad die aankoms van die polisiekontingent gade geslaan en het gevolglik op 1 April ' $n$ dringende telegram aan die Goewerneur-Generaal gestuur, met die versoek om in die naam van die Britse koning in te gryp om bloedvergieting te voorkom. ${ }^{35}$ In ' $n$ tweede telegram, gedateer 4 April, het hulle die Goewerneur-Generaal meegedeel: "De onbewapende voor vreede smeekende bastard nazie doen een mal de verzoek niet om onze onschuldige bloet te vergieten maar een onpaartydige ondersoek." ${ }^{36}$

Die Eerste Minister het skerp gereageer op dié telegramme en die Nuwe Raad gewaarsku dat die burgers hulle eers moes onderwerp aan die wette, alvorens verdere onderhandelinge hervat kon word. Hy het hulle verseker dat die polisie nie onnodige geweld sou gebruik nie, maar beklemtoon dat dit van hulle sou afhang tot welke mate geweld gebruik sou word. Hy het hulle vir die laaste keer gewaarsku "dat die Regering dit ernstig bedoel en dat indien die Regering tot gebruik van geweld oorgaan die Burgery daarvoor verantwoordelik sal wees." ${ }^{37}$

In die tussentyd het die Nuwe Raad hom ook tevergeefs $^{38}$ op die Volkebond beroep. ${ }^{39}$ Te midde van dié vurige pleidooie aan die Goewerneur-Generaal en die Volkebond sowel as ' $n$ beroep op hulle ondersteuners om die Administrasie ten alle koste teen te staan, het laasgenoemde inderhaas finale voorbereidings getref om die onrus in die RehobothGebiet in die kiem te smoor.

\section{Onderdrukking van die opstand}

Teen Saterdagmiddag 4 April was tussen 600 en 700 Basterburgers, Herero's en ander nie-blankes in Rehoboth byeen. Die kaptein en ander leiers van die opposisiegroep het in die kantore van die Nuwe Raad vergader en is dag en nag deur gewapende wagte bewaak. Die opposisiegroep het alle moontlike maatreëls getref om nie deur die vyand verras te word nie. Berede sowel as onberede brandwagte is gereeld teen sonsondergang uitgestuur. ${ }^{40}$ Uit ' $n$ brief van die Nuwe Raad aan kolonel De Jager, gedateer 4 April, het dit duidelik geblyk dat die opposisiegroep hulle nie sonder geweld aan die gesag van die Administrasie sou onderwerp nie..$^{41}$
Kolonel De Jager was bevrees dat die opposisiegroep kon uitwyk na byvoorbeeld die bergvestings van Sam Kubis of Naukluft. Hy het derhalwe ná oorlegpleging met die Administrateur besluit om, met die veronderstelling dat die drie vliegtuie onder bevel van luitenant-kolonel Van Ryneveld betyds opdaag, nie later nie as Sondag 5 April 1925 teen die opposisiegroep op te tree. ${ }^{42}$

Kolonel De Jager het besluit om die hele Rehobothdorpie te omsingel. Die burgermag is met die doel voor oë in drie afdelings verdeel. Afdeling A onder leiding van kommandant $L$. Rautenbach moes op die rante wes van Rehoboth en Afdeling $B$ onder bevel van veldkaptein J. Balt aan die oostekant van Rehoboth stelling inneem. Afdeling $\mathrm{C}$, die enigste berede afdeling, onder leiding van veldkaptein J.J. Smith, moes die oorblywende moontlike ontsnappingsroetes bewaak. Die omsingelingsaksie moes teen dagbreek op Sondag 5 April 1925 voltooi wees. ${ }^{43}$

Kolonel De Jager het besluit om die polisiekontingent in Rehoboth-dorp aan te wend en het sy beweegrede vir die stap só verwoord: "I decided to utilize the Police Detachment, a body of trained and highly disciplined men, inside the village, where the initial moves to our operations, upon which so much depended, required tactful and skilful handling." ${ }^{44}$

Die taak van die lugmageenheid was om ' $n$ demonstrasievlug teen 08:00 met die verstryking van die ultimatum oor Rehoboth uit te voer. Hulle moes daarmee voortgaan indien die opposisiegroep nie oorgegee het nie en ' $n$ ogie hou oor die optrede van die landmagte. Bombardering deur die vliegtuie sou slegs in geval van dringende noodsaaklikheid geskied. ${ }^{45}$

Teen dagbreek op Sondag 5 April was die verskillende afdelings reeds in posisie. Luitenante J.D. Celliers en A.J. Coetzee het om 06:50 na die Nuwe Raadskantore vertrek om persoonlik die ultimatum aan Nicolaas van Wijk, kaptein van die Nuwe Raad, te oorhandig. ${ }^{46}$

Kolonel De Jager het geëis dat die gedagvaarde persone uitgelewer word en die opposisiegroep teen 08:00 onvoorwaardelik oorgee en hulle wapens

\footnotetext{
Sentrale Argiefbewaarplek (SAB) GG 1558:50/1166, Telegram Captain and Volksraad/Governor-General, 1.04.1925.

SAB GG 1558:50/1166, Telegram Kaptein, Volks Raad en Parliament Burger[raad]/General Gouveneur, 4.04.1925.

NAW SWAAA206/3 Bastard Gebiet Rehoboth. Rehoboth Matters (vol 7), Telegram Hoofd/Magistraat Manning, 4.04.1925.

LNA, 1919-1927, 1/1347/37888, Letter V. Catastini/Captain of Volksraad, 3.04.1925.

9 LNA, 1919-1927, 1/1347/37888, Telegram Kaptien (sic) en Volks Raad/Nations Généva, 1.04.1925; NAW SWAAA206/3 Bastard Gebiet Rehoboth. Rehoboth Matters (vol 6), Telegram Secretary [for South West Africa]/Hoofd, 31.03.1925.

40 NAW SWAAA206/3(vol 7a) Rehoboth Matters: Report Colonel M.J. de Jager/Secretary for South West Africa, 16.06.1925, p. 10.

1 NAW SWAAA206/3(vol 7a) Rehoboth Matters: Brief N. van Wijk et al./De Jager, 4.04.1925.

2 NAW SWAAA206/3(vol 7a) Rehoboth Matters: Report Colonel M.J. de Jager/Secretary for South West Africa, 16.06.1925, p. 11.

43 NAW SWAAA206/3(vol 7a) Rehoboth Matters: Report Colonel M.J. de Jager/Secretary for South West Africa, 16.06.1925, pp. 11 13.

44 NAW SWAAA206/3(vol 7a) Rehoboth Matters: Report Colonel M.J. de Jager/Secretary for South West Africa, 16.06.1925, p.14.

45 NAW SWAAA206/3(vol 7a) Rehoboth Matters: Report Colonel M.J. de Jager/Secretary for South West Africa, 16.06.1925, p. 14.

46 NAW SWAAA206/3(vol 7a) Rehoboth Matters: Report Colonel M.J. de Jager/Secretary for South West Africa, 16.06.1925, p. 15.
} 
oorhandig. Hy het hul verseker dat "....indien dit nie geskied by acht uur hede morre sal ek verplig wees om handelend op te tree en, indien nodig, geweld te gebruik". Hy het verder gewaarsku dat indien hulle nie aan die ultimatum gehoor wou gee nie, die vrouens, kinders en alle nie-strydende persone na die noordekant van die trollielyn verskuif moes word waar hy hul veiligheid gewaarborg het. ${ }^{47}$

Kort ná die oorhandiging van die ultimatum aan Van Wijk het ' $n$ hele aantal Bastermans en ' $n$ aantal Herero's inderhaas na die kantore van die Nuwe Raad gegaan. ' $n$ Aantal mans, vrouens en kinders het met van hul besittings na die noordekant van die trollielyn beweeg. ${ }^{48}$

Teen ongeveer 07:30 het twee Basterboodskappers by die Magistraatskantoor opgedaag en ' $n$ brief aan De Jager oorhandig. ${ }^{49}$ Die opposisiegroep het hom versoek om aan hulle uitstel te verleen tot 12:00 die volgende dag om die ultimatum te oorweeg. ${ }^{50}$ Daarop het kolonel De Jager ferm gereageer: "My vorige besluit bly staan. Geen verlenging van tyd sal gegee word. Die tyd nadert, dus wees haastig met jullie besluit." ${ }^{51}$

Teen 07:50 het ' $n$ verdere kommunikasie van die opposisiegroep De Jager bereik..$^{52}$ Uit die brief het dit duidelik geblyk dat die opposisiegroep nie van plan was om gehoor te gee aan die ultimatum nie. Hulle wou ook nie die vrouens en kinders ten noorde van die trollielyn verskuif nie. Die opposisiegroep het waarskynlik gehoop dat De Jager nie sou aanval terwyl die vrouens en kinders in hul geledere was nie. Hulle het hom verseker dat hulle nie die wapen sou opneem teen "de Majesteits Regering" nie. ${ }^{53}$

Maasdorp was teenwoordig toe De Jager die jongste brief van die opposisiegroep ontvang het. Op sy versoek het hy saam met die boodskapper na die kantore van die Nuwe Raad gegaan in ' $n$ poging om hulle tot ander insigte te bring. Maasdorp het teen 08:05 aan De Jager gerapporteer dat die opposisiegroep nie van plan was om oor te gee nie. ${ }^{54}$
Intussen het die drie vliegtuie op die bestemde tyd by Rehoboth-stasie opgestyg, en tien minute later het hulle oor die dorp gesirkel. De Jager het onmiddellik die afdelings van die Burgermag opdrag gegee om in te beweeg. ' $n$ Afdeling van die Suidwes-Afrikaanse Polisie onder bevel van luitenant Uys het na die kantore van die Nuwe Raad beweeg. met die doel om die elf Basters wat die opposisiegroep geweier het om uit te lewer, te arresteer. Met sy aankoms by die Raadskantore het luitenant Uys die name van die elf Basters aan Jakobus Beukes oorhandig. ${ }^{55}$

Jakobus Beukes het hom egter meegedeel dat hulle nie die betrokke persone sou uitlewer nie en dat hulle met De Jager wou onderhandel. Luitenant Uys het hulle vyf minute gegee om die elf uit te lewer. Die opposisiegroep het nie daaraan gehoor gegee nie, en die polisie het gevolglik die Raadskantore bestorm. Vrouens het tussen die polisie en die opposisiegroep inbeweeg in ' $n$ poging om te verhoed dat die polisie die Raadskantore bereik. Die vrouens is met geweld verwyder, en nadat versterkings opgedaag het, is die opposisiegroep by die Raadskantore almal met geweld gearresteer. Ander betrokkenes, onder andere die Herero's en ander nie-blankes wat ongeveer 40 meter suidwes van die Raadskantore versamel het, is intussen ook gearresteer. Die hele operasie is binne ' $n$ uur sonder enige lewensverlies afgehandel: ' $n$ flink militêre aksie op die grond, onder dekking van Pierre van Ryneveld se dreunende vliegtuie in die lug. ${ }^{56}$

Ongeveer 15 wapens is van die groep by die Raadskantore afgeneem en ' $n$ soektog van huis tot huis het nog 162 wapens opgelewer. ${ }^{57}$ De Jager het op Maandag 6 April 1925 'n Krygswetregulasie uitgereik waarvolgens die Basters en nie-blankes woonagtig in die Rehoboth-Gebiet alle wapens, ammunisie en plofstof moes inlewer. Teen 24 April 1925 is ' $n$ verdere 313 wapens oorhandig. Na behoorlike registrasie is die wapens van die sogenaamde lojale Basters teruggegee. Die res is gekonfiskeer en na Windhoek geneem..$^{58}$

47 NAW SWAAA206/3(vol 7a) Rehoboth Matters: Ultimatum Kolonel M. J. de Jager/[Kaptein N. van Wijk], 5.04.1925; The Windhoek Advertiser, 8.04.1925.

48 NAW SWAAA206/3(vol 7a) Rehoboth Matters: Report Colonel M.J. de Jager/Secretary for South West Africa, 16.06.1925, p. 16.

49 NAW SWAAA206/3(vol 7a) Rehoboth Matters: Report Colonel M.J. de Jager/Secretary for South West Africa, 16.06.1925, p. 16.

so NAW SWAAA206/3(vol 7a) Rehoboth Matters: Brief N. van Wijk et al./De Jager, 5.04.1925.

5. NAW SWAAA206/3(vol 7a) Rehoboth Matters: Brief De Jager/N. van Wijk, 5.04.1925; LRE 1/1/3: Notule [Hofverrigtinge, 7 April 1925], p. 11.

52 NAW SWAAA206/3(vol 7a) Rehoboth Matters: Report Colonel M.J. de Jager/Secretary for South West Africa, 16.06.1925, p. 17.

53 NAW SWAAA206/3(vol 7a) Rehoboth Matters: Brief N. van Wijk/De Jager, 5.04.1925

54 NAW SWAAA206/3(vol 7a) Rehoboth Matters: Report Colonel M.J. de Jager/Secretary for South West Africa, 16.06.1925, p. 17.

55 NAW SWAAA206/3(vol 7a) Rehoboth Matters: Report Colonel M.J. de Jager/Secretary for South West Africa, 16.06.1925, pp. 1718; 20; LRE 1/1/3: Notule [Hofverrigtinge, 9.04.1925], p. 1.

56 NAW SWAAA206/3(vol 7a) Rehoboth Matters: Report Colonel M.J. de Jager/Secretary for South West Africa, 16.06.1925, pp. 1822; A206/3(vol 7) Rehoboth Matters: Telegram Administrator/Secretary [for South West Africa], 5.04.1925; The Times, 6.04.1925; The New York Times, 6.04.1925.

57 NAW SWAAA206/3(vol 7a) Rehoboth Matters: Report Colonel M.J. de Jager/Secretary for South West Africa, 16.06.1925, p. 19; Cape Times, 7.04.1925.

58 NAW SWAAA206/3(vol 7a) Rehoboth Matters: Telegram Hoofd/ Secretary [for South West Africa], 14.04.1925; Report Colonel M.J. de Jager/Secretary for South West Africa, 16.06.1925, pp. 19; 22-23; A312 vol 20 item 79: Telegram Mobilize(De Jager)/ Administrator, 7.04.1925, pp. 3-4. 


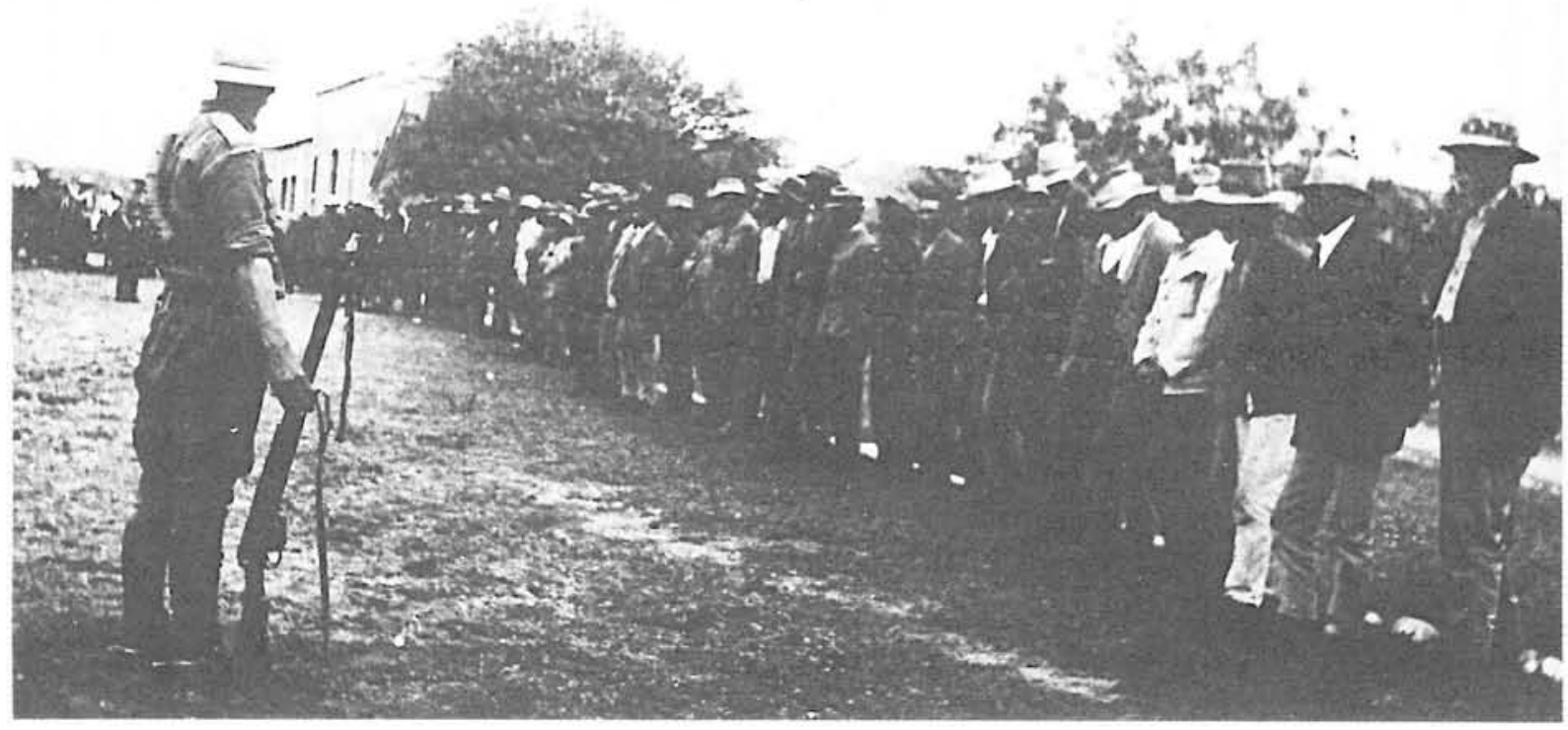

Polisie bewaak Bastergevangenes, 5 April 1925

Nasionale Argief, Windhoek

\section{Demobilisasie}

Kort na afloop van die veldtog is begin met die demobilisering van die magte. Burgermageenhede wat nog onderweg was na Rehoboth, ongeveer 200 in getal, is beveel om terug te keer. Benewens Afdeling A van die burgermag (soldate van Windhoek en Okahandja) en die polisiekontingent, het alle ander burgermageenhede die middag van 5 April 1925 na Rehoboth-stasie vertrek. Hulle het die volgende dag per spoor na hul onderskeie distrikte teruggekeer. Burgermageenhede van Windhoek en Okahandja het op Woensdag 8 April 1925 vertrek, terwyl 100 polisiemanne twee dae later na hul onderskeie polisiestasies teruggekeer het. ${ }^{59}$

Die oorblywende lede van die polisiemag is tussen 10 en 22 April 1925 aangewend om die hele Rehoboth-Gebiet deeglik te patrolleer. Teen 30 April 1925 het die situasie in die Rehoboth-Gebiet tot so ' $n$ mate genormaliseer dat die plaaslike polisiekontingent weer gewone sterkte was. ${ }^{60}$

Die lugmagkontingent onder luitenant-kolonel Pierre van Ryneveld het op 8 April na Windhoek vertrek. ${ }^{61}$ Die Suid-Afrikaanse Minister van Verdediging het, na verskeie oorredingspogings ${ }^{62}$ deur die Administrateur, uiters teësinnig toestemming verleen dat bomdemonstrasies met brisant- en nie oefenbomme in die nie-blanke reservate kon plaasvind. ${ }^{63}$ Die Administrateur wou deur dié magsvertoon vrees by voornemende opstandelinge inboesem. ${ }^{64}$ Van Ryneveld en sy span het gevolglik verskeie bomdemonstrasies by onder andere Ondongua, Okahandja, Windhoek, Vaalgras en Scheidhof uitgevoer. ${ }^{65}$

Kolonel De Jager het die suksesvolle onderdrukking van die opstand en die feit dat dit sonder enige lewensverlies verloop het, grotendeels toegeskryf aan die teenwoordigheid van luitenant-kolonel Pierre van Ryneveld en sy vliegtuie. Hy het dit só verduidelik: "The appearance of the much dreaded aeroplanes on the scene at the crucial moment and their manoeuvering over the village inspired awe and completely distracted the minds of the malcontents from the Land Force." 66

' $n$ Mens kan jou die uitwerking van die gedreun van die laag sirkelende vliegtuie (seker van die "Scouts" wat in 1920 aangeskaf is ${ }^{67}$ ) op die ongesofistikeerde

59 NAW SWAAA206/3(vol 7a) Rehoboth Matters: Report Colonel M.J. de Jager/Secretary for South West Africa, 16.06.1925, p. 25.

60 NAW SWAAA206/3(vol 7a) Rehoboth Matters: Report Colonel M.J. de Jager/Secretary for South West Africa, 16.06.1925, pp. 2526.

61 NAW SWAAA206/3(vol 7a) Rehoboth Matters: Report Colonel M.J. de Jager/Secretary for South West Africa, 16.06.1925, p. 26.

62 NAWA312 vol 20 item 79: Telegram Administrator/Minister of Defence, [9.04.1925]; A206/3(vol. 7) Rehoboth Matters: Telegram Administrator/Secretary [for South West Africa], 9.04.1925; A206/3(vol. 7a) Rehoboth Mattters: Telegram Hoofd/Secretary [for South West Africa], 11.04.1925.

63 NAW SWAAA206/3(vol 7a) Rehoboth Matters: Telegram Hoofd/ Secretary [for South West Africa], 13.04.1925, p. 1.

64 NAW SWAAA206/3(vol 7) Rehoboth Matters: Telegram Secretary [for South West Africa]/Hoofd(Cape Town), 9.04.1925.

65 NAW SWAAA206/3(vol 7a) Rehoboth Matters: Telegram Cosaaf(Kolonel van Ryneveld)/Hoofd, 20.04.1925; Verkorte jaarverslag van die Departement van Verdediging diensjaar tot 30 Junie 1925, p. 24; Allgemeine Zeitung, 22.04.1925; The Windhoek Advertiser, 22.04.1925.

66 NAW SWAAA206/3(vol 7a) Rehoboth Matters: Report Colonel M.J. de Jager/Secretary for South West Africa, 16.06.1925, pp. 2627.

${ }_{67}$ Kyk Suid-Afrikaanse Weermag/South African Defence Force, Suid-Afrikaanse Weermag Oorsig/South African Defence Force Review (Walker-Ramus Trading Co. S.A. (Pty) Ltd., Marine Parade, s.a.), p.43. 
Basters en hulle medestanders met geringe inspanning van die verbeelding duidelik voorstel. Op die grond is daar die goed afgerigte polisie en melisie; in die lug die donderende werktuie van die duiwel met die moontlike verwoestende uitwerking van hulle dreigende bomme waarvan miskien al gehoor is. ' $n$ Mens moes senuwees van staal hê om jou teen so ' $n$ vyand te verweer - en die malkontente was reeds ontsenu deur die lang gedraal met die onderhandelinge. Pierre van Ryneveld het met sy ontsagwekkende paar vliegtuie die deurslag gegee in hierdie ongelyke stryd en ook daartoe bygedra om sy reeds goed gevestigde roem as vlieënier te verstewig, sodat hy nog in sy lewe ' $n$ legende onder lugmagmanne en die breër bevolking geword het. In die annale van die Suid-Afrikaanse lugvaart leef sy roem onaangetas en met reg ongeskonde voort: die Vrystaatse boerseun wat die lugmagheld sir Pierre van Ryneveld geword het, pionier en grondvester van ons lugmag. 